\title{
Ab Initio Study of Mechanism of Forming Germanic Bis-Heterocyclic Compound between Dimethyl-Germylene Carbene $\left(\mathrm{Me}_{2} \mathrm{Ge}=\mathrm{C}\right.$ :) and Acetone
}

\author{
Xiuhui Lu, ${ }^{*}$ Xin Che, Zhenxia Lian, and Yongqing Li \\ School of Chemistry and Chemical Engineering, University of Jinan, Jiweilu 106, Jinan, Shandong 250022, P. R. China \\ ${ }^{*}$ E-mail: lxh@ujn.edu.cn \\ Received July 29, 2010, Accepted October 25, 2010
}

\begin{abstract}
The mechanism of the cycloaddition reaction of forming germanic bis-heterocyclic compound between singlet dimethylgermylene carbene and acetone has been investigated with $\mathrm{CCSD}(\mathrm{T}) / \mathrm{B} 3 \mathrm{LYP} / 6-31 \mathrm{G}^{*}$ method. From the potential energy profile, it can be predicted that, this reaction has one dominant channel. The presented rule of this dominant channel is that the two reactants firstly form a four-membered ring carbene (RC4) through the [2+2] cycloaddition reaction. Due to $\mathrm{sp}^{2}$ hybridization of carbene $\mathrm{C}$ atom in $\mathrm{RC} 4, \mathrm{RC} 4$ further combines with acetone to form a reactant complexe (RC5). Due to the further $\mathrm{sp}^{3}$ hybridization of carbene $\mathrm{C}$ atom in $\mathrm{RC} 4, \mathrm{RC} 5$ isomerizes to a germanic bisheterocyclic compound (P6) via the transition state (TS5).
\end{abstract}

Key Words: Dimethyl-germylene carbene, Cycloadditional reaction, Potential energy surface

\section{Introduction}

Since unsaturated carbene was recognized as an active intermediate in 1960s, it has not only attracted much attention from theoretical chemists but also has been practically applied to organic chemistry. ${ }^{1,2}$ For example, it has been proved that unsaturated carbene can provide a simple and direct way for synthesizing the small-ring, highly strained compounds as well as those that can hardly be synthesized through conventional ways. ${ }^{2}$ So far, much theoretical study has been done on the rearrangement reaction ${ }^{3,4}$ and the insertion reaction ${ }^{5,6}$ of alkylidene carbene $\left[\mathrm{R}_{1}, \mathrm{R}_{2} \mathrm{C}=\mathrm{C}\right.$ : $\left.\left(\mathrm{R}_{1}, \mathrm{R}_{2}=\mathrm{H}, \mathrm{Me}, \mathrm{F}, \mathrm{Cl}, \mathrm{Br}, \mathrm{Ph}, \mathrm{Ar} \ldots \ldots\right)\right]$. Apeloig and $\mathrm{Fox}^{7,8}$ have made experimental and theoretical studies on the three-dimensional selectivity of substituting groups from the products of the vinylidene-olefins addition. And we have done systemic studies on the cycloaddition reaction of alkylidene carbene ${ }^{9-13}$ However, studies of unsaturated carbene have so far been limited to alkylidene carbene and its reactions and there has been no published report of studies of germylene carbene $\left(\mathrm{H}_{2} \mathrm{Ge}=\mathrm{C}\right.$ : $)$ and its derivatives $\left[\mathrm{R}_{1}, \mathrm{R}_{2} \mathrm{Ge}=\mathrm{C}\right.$ : $\left(\mathrm{R}_{1}, \mathrm{R}_{2}=\mathrm{Me}, \mathrm{F}, \mathrm{Cl}, \mathrm{Br}, \mathrm{Ph}, \mathrm{Ar}\right.$.....)]. It is a new branch of unsaturated carbene chemistry. It is quite difficult to investigate mechanism of cycloaddition reaction directly by experimental methods due to the high activity of germylene carbene; therefore, the theoretical study is more practical. Compared with the cycloaddition reaction of alkylidene carbene, ${ }^{2}$ cycloaddition reaction of germylene carbene $(\mathrm{H} 2 \mathrm{Ge}=\mathrm{C}$ :)and its derivatives, which are significant for the synthesis of small-ring and bisheterocyclic compounds with Ge. In addition, the study extends research area and enriches the research content of carbene chemistry. To explore the rules of cycloaddition reaction between germylene carbene and its derivatives and the asymmetric $\pi$ bonded compounds, taking into account the dimethyl-germylene carbene $\left(\mathrm{Me}_{2} \mathrm{Ge}=\mathrm{C}\right.$ :) is more representative, dimethyl-germylene carbene and acetone were selected as model molecules. The cycloaddition reaction mechanism was investigated and analyzed theoretically. The results show that this reaction pro- ceeds in the following five possible pathways (considering the methyl transfer):
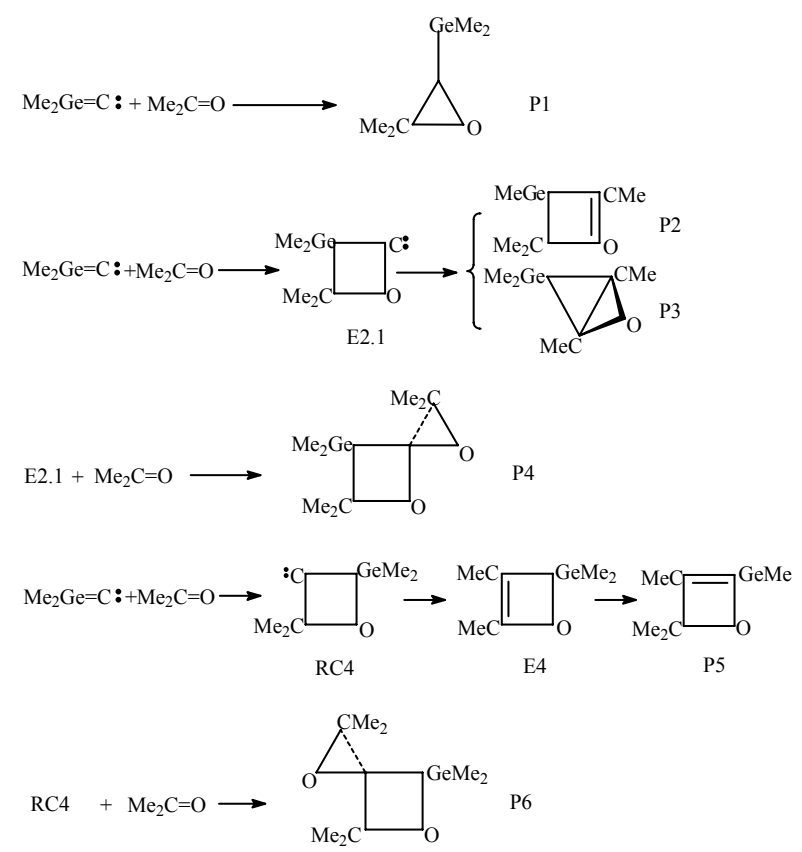

\section{Computational Methods}

B3LYP/6-31 $\mathrm{G}^{* 14}$ implemented in the Gaussian98 package is employed to locate all the stationary points along the reaction pathways. Full optimization and vibrational analysis are done for the stationary points on the reaction profile. Zeropoint energy and $\operatorname{CCSD}(\mathrm{T})$ corrections are included for the energy calculations. In order to further confirm the correctness of the relevant species, vibration analysis is included, and the intrinsic reaction coordinate (IRC) ${ }^{15,16}$ is also calculated for all the transition states appearing on the potential energy profile. 


\section{Results and Discussions}

Reaction(1): Channel of Forming the Three-Membered Ring Product P1. Theoretical calculations show that the ground state of dimethyl-germylene carbene is singlet state. The geometrical parameters for the reactant complexe ( $\mathrm{RC} 1)$, transition state
(TS1) and product (P1) appearing in reaction(1) between dimethyl-germylene carbene and acetone are given in Fig. 1. The energies are listed in Table 1, and the potential energy surface for the cycloaddition reaction is shown in Fig. 2.

The unique imaginary frequency of the transition state TS1 through vibrational analysis is $207.1 \mathrm{i}$, therefore, this transition
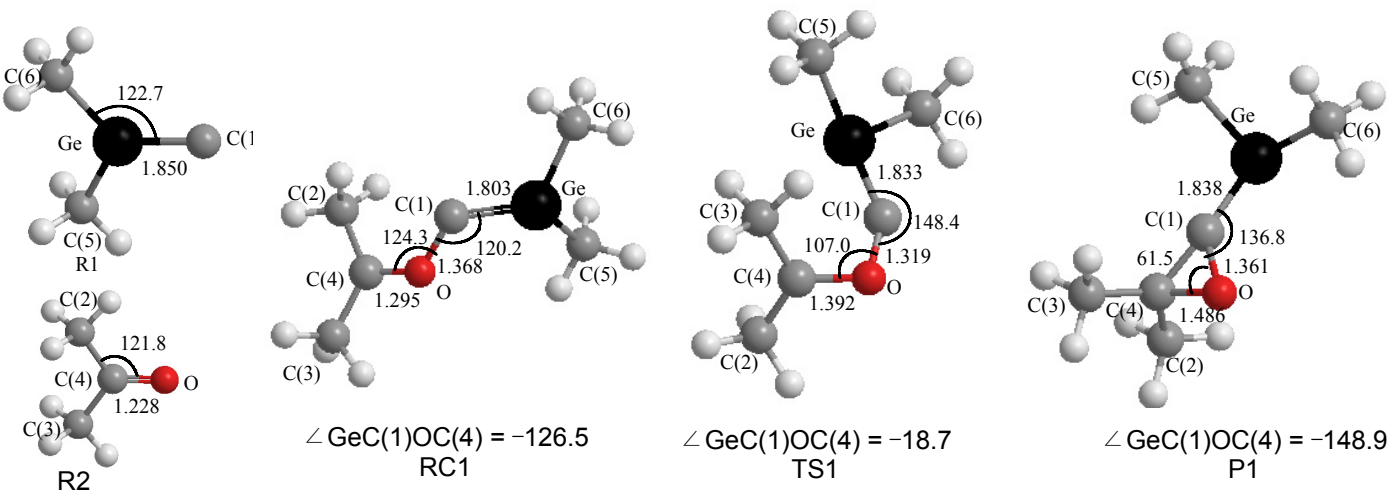

Figure 1. Optimized B3LYP/6-31G* geometrical parameters and the atomic numbering for the species in cycloaddition reaction(1). Lengths are in $\AA$ and angles in degree.

Table 1. Zero point energy (ZPE, hartree), total energies $\left(E_{\mathrm{T}}\right.$, hartree) and relative energies $\left(E_{\mathrm{R}}, \mathrm{kJ} / \mathrm{mol}\right)$ for the species from various theoretical methods

\begin{tabular}{|c|c|c|c|c|c|c|}
\hline \multirow{2}{*}{ Reaction } & \multirow{2}{*}{ Species } & \multirow{2}{*}{ ZPE } & \multicolumn{2}{|c|}{ B3LYP/6-31G* } & \multicolumn{2}{|c|}{$\mathrm{CCSD}(\mathrm{T}) / / \mathrm{B} 3 \mathrm{LYP} / 6-31 \mathrm{G}^{*}$} \\
\hline & & & ${ }^{a} E_{\mathrm{T}}$ & ${ }^{b} E_{\mathrm{R}}$ & ${ }^{a} E_{\mathrm{T}}$ & ${ }^{b} E_{\mathrm{R}}$ \\
\hline \multirow{4}{*}{ Reaction(1) } & $\mathrm{R} 1+\mathrm{R} 2$ & 0.16004 & -2385.72344 & 0.0 & -2383.09717 & 0.0 \\
\hline & $\mathrm{RC} 1$ & 0.16384 & -2385.77345 & -131.3 & -2383.14187 & -117.4 \\
\hline & TS1(RC1-P1) & 0.16237 & -2385.73887 & -40.5 & -2383.12111 & -62.9 \\
\hline & $\mathrm{P} 1$ & 0.16563 & -2385.84427 & -317.2 & -2383.21813 & -317.6 \\
\hline \multirow{10}{*}{ Reaction(2) } & $\mathrm{R} 1+\mathrm{R} 2$ & 0.16004 & -2385.72344 & 0.0 & -2383.09717 & 0.0 \\
\hline & $\mathrm{RC} 1$ & 0.16384 & -2385.77345 & -131.3 & -2383.14187 & -117.4 \\
\hline & TS2.1(RC1-E2.1) & 0.16253 & -2385.75378 & -79.6 & -2383.12550 & -74.4 \\
\hline & E2.1 & 0.16414 & -2385.81150 & -231.2 & -2383.18783 & $-238 . .0$ \\
\hline & TS2.2(E2.1-E2.2) & 0.16260 & -2385.74966 & -68.8 & -2383.12044 & -61.1 \\
\hline & E2.2 & 0.16412 & -2385.78336 & -157.3 & -2383.15463 & -150.9 \\
\hline & $\mathrm{TS} 2.3(\mathrm{E} 2.2-\mathrm{P} 2)$ & 0.16292 & -2385.74788 & -64.1 & -2383.12012 & -60.3 \\
\hline & P2 & 0.16686 & -2385.85636 & -349.0 & -2383.22739 & -341.9 \\
\hline & TS3.1(E2.1-P3) & 0.16194 & -2385.71245 & 28.9 & -2383.08632 & 28.5 \\
\hline & P3 & 0.16522 & -2385.84127 & -309.4 & -2383.21591 & -311.8 \\
\hline \multirow{4}{*}{ Reaction(3) } & $\mathrm{E} 2.1+\mathrm{R} 2$ & 0.24823 & -2578.88311 & 0.0 & -2575.68176 & 0.0 \\
\hline & $\mathrm{RC} 3$ & 0.25312 & -2578.91455 & -82.5 & -2575.69250 & -28.2 \\
\hline & TS3(RC3-P4) & 0.25175 & -2578.89895 & -41.6 & -2575.66830 & 35.3 \\
\hline & P4 & 0.25456 & -2578.96410 & -212.6 & -2575.77082 & -233.8 \\
\hline \multirow{6}{*}{ Reaction(4) } & $\mathrm{R} 1+\mathrm{R} 2$ & 0.160039 & -2385.72344 & 0.0 & -2383.09717 & 0.0 \\
\hline & $\mathrm{RC} 4$ & 0.164397 & -2385.79544 & -189.0 & -2383.17699 & -209.6 \\
\hline & TS4.1(RC4-E4) & 0.163193 & -2385.79085 & -177.0 & -2383.17161 & -195.4 \\
\hline & E4 & 0.166201 & -2385.92851 & -538.4 & -2383.30444 & -544.2 \\
\hline & TS4.2(E4-P5) & 0.163974 & -2385.77037 & -123.2 & -2383.15135 & -142.2 \\
\hline & $\mathrm{P} 5$ & 0.167701 & -2385.86385 & -368.6 & -2383.24682 & -392.9 \\
\hline \multirow{4}{*}{ Reaction(5) } & $\mathrm{RC} 4+\mathrm{R} 2$ & 0.248487 & -2578.86705 & 0.0 & -2575.67093 & 0.0 \\
\hline & $\mathrm{RC} 5$ & 0.253222 & -2578.92949 & -163.9 & -2575.73393 & -165.4 \\
\hline & TS5(RC5-P6) & 0.251691 & -2578.900258 & -87.2 & -2575.71258 & -109.4 \\
\hline & P6 & 0.254701 & -2578.98906 & -320.3 & -2575.80302 & -346.8 \\
\hline
\end{tabular}

${ }^{a} E_{\mathrm{T}}=E($ Species $)+\mathrm{ZPE},{ }^{b} E_{\mathrm{R}}=E_{\mathrm{T}}-E_{(\mathrm{R} 1+\mathrm{R} 2)},{ }^{b} E_{\mathrm{R}}=E_{\mathrm{T}}-E_{(\mathrm{E} 2.1+\mathrm{R} 2)},{ }^{b} E_{\mathrm{R}}=E_{\mathrm{T}}-E_{(\mathrm{RC} 4+\mathrm{R} 2)}$ 


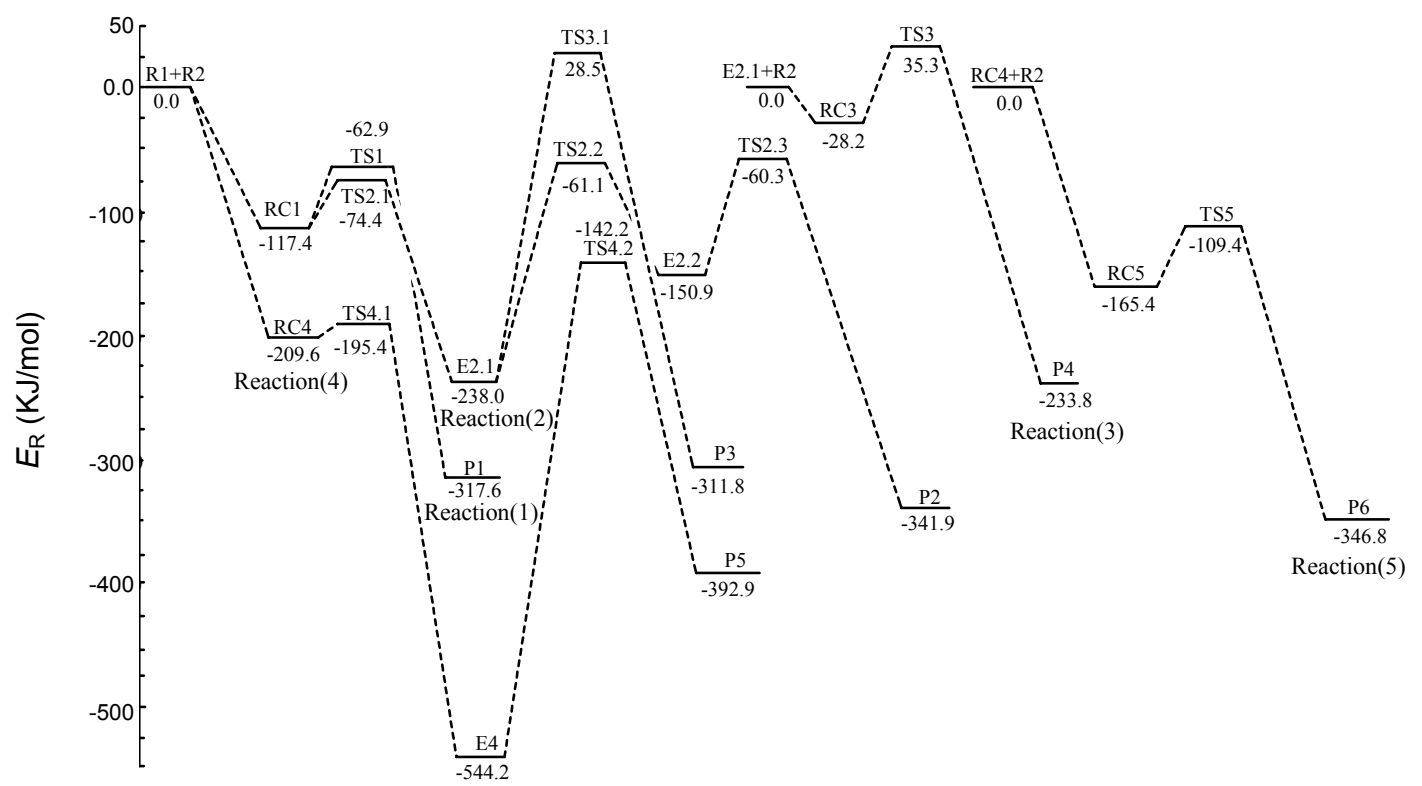

Figure 2. The potential energy surface for the cycloaddition reactions between dimethyl-germylene carbene and acetone with $\mathrm{CCSD}(\mathrm{T}) / / \mathrm{B} 3 \mathrm{LYP} /$ 6-31G*.

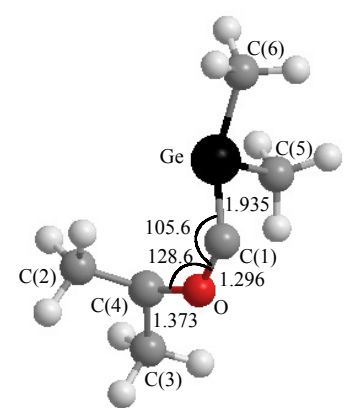

$$
\angle \mathrm{GeC}(1) \mathrm{OC}(4)=-36.9
$$

TS2.1

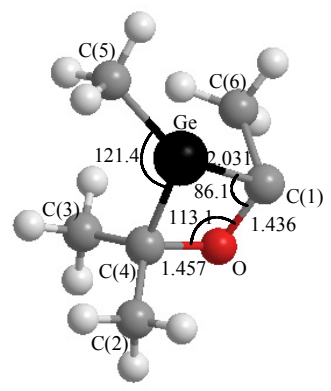

$\angle \mathrm{GeC}(1) \mathrm{OC}(4)=6.0$

TS2.3

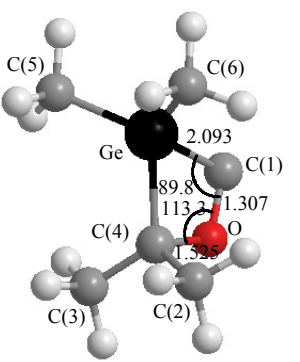

$\angle \mathrm{GeC}(1) \mathrm{OC}(4)=0.1$

E2.1

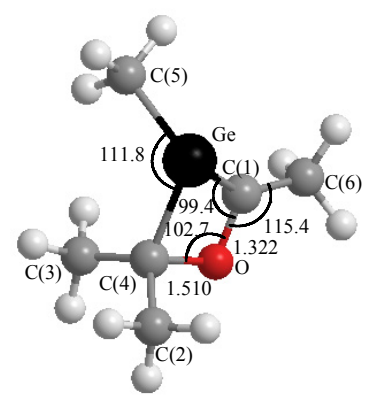

$\angle \mathrm{GeC}(1) \mathrm{OC}(4)=15.6$

P2

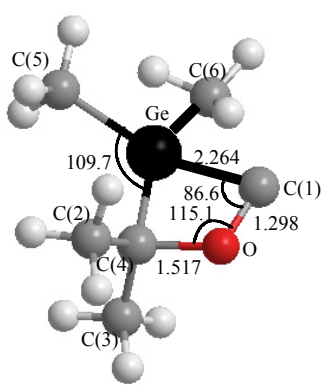

$\angle \mathrm{GeC}(1) \mathrm{OC}(4)=-10.2$ TS2.2

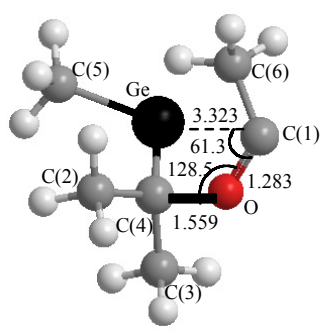

$\angle \mathrm{GeC}(1) \mathrm{OC}(4)=-27.8$

E2.2
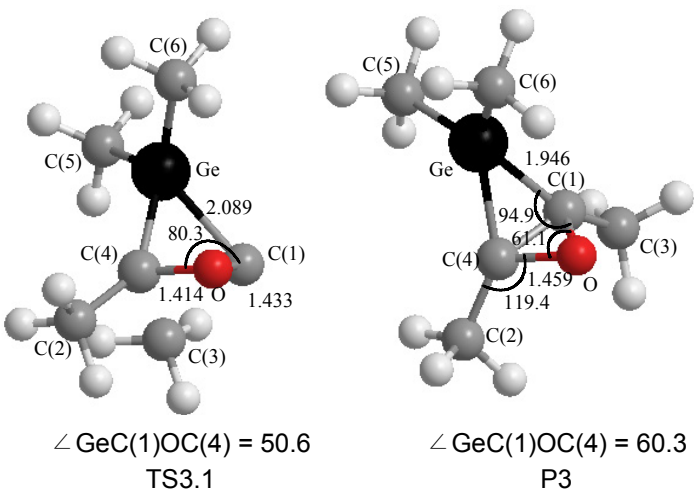

Figure 3. Optimized B3LYP/6-31G* geometrical parameters of TS2.1, TS2.2, TS2.3, TS3.1, E2.1, E2.2, P2, P3 and the atomic numbering for cycloaddition reaction(2). Lengths are in $\AA$ and angles in degree.

state can be affirmed as the real one. IRC (with the step-length of $0.1 \mathrm{amu}^{-1 / 2} \mathrm{bohr}$ ) analysis of TS1 confirms that TS1 connects $\mathrm{RC} 1$ and P1. According to Fig. 2, it can be seen that reaction (1) is composed of two steps: the first one is that the two reactants $(\mathrm{R} 1, \mathrm{R} 2)$ firstly form a complexe (RC1), which is a barrierfree exothermic reaction with $\Delta \mathrm{E}$ of $117.4 \mathrm{~kJ} / \mathrm{mol}$; and the second one is an isomerization of $\mathrm{RC} 1$ to a three-membered ring product
P1 via a transition state TS1, with an energy barrier of 54.5 $\mathrm{kJ} / \mathrm{mol}$.

Reaction(2): Channels of Forming Four-Membered Ring Intermediate (E2.1) and $\mathbf{C H}_{3}$-Transfer Product (P2, P3). The geometrical parameters for the transition states (TS2.1, TS2.2, TS2.3, TS3.1), intermediates (E2.1, E2.2) and products (P2, P3) appearing in reaction(2) between dimethyl-germylene carbene 


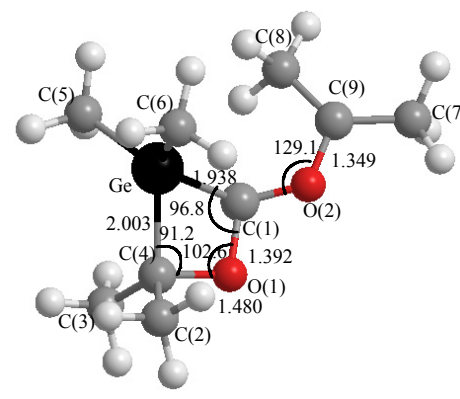

$$
\begin{gathered}
\angle \mathrm{GeC}(1) \mathrm{O}(1) \mathrm{C}(4)=0.6 \\
\angle \mathrm{O}(2) \mathrm{C}(1) \mathrm{O}(1) \mathrm{C}(4)=173.6 \\
\angle \mathrm{C}(9) \mathrm{O}(2) \mathrm{C}(1) \mathrm{O}(1)=-175.4
\end{gathered}
$$

RC3

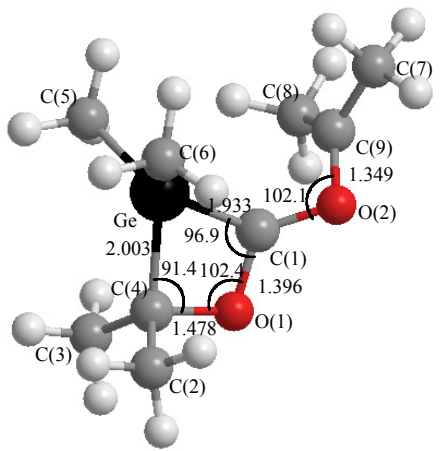

$\angle \mathrm{GeC}(1) \mathrm{O}(1) \mathrm{C}(4)=0.1$

$\angle \mathrm{O}(2) \mathrm{C}(1) \mathrm{O}(1) \mathrm{C}(4)=153.3$

$\angle \mathrm{C}(9) \mathrm{O}(2) \mathrm{C}(1) \mathrm{O}(1)=149.0$

TS3

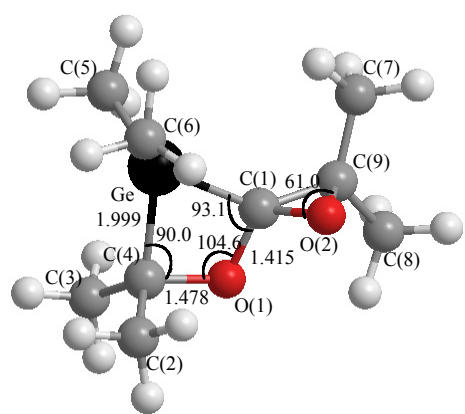

$\angle \mathrm{GeC}(1) \mathrm{O}(1) \mathrm{C}(4)=-11.7$

$\angle \mathrm{O}(2) \mathrm{C}(1) \mathrm{O}(1) \mathrm{C}(4)=119.3$

$\angle \mathrm{C}(9) \mathrm{O}(2) \mathrm{C}(1) \mathrm{O}(1)=112.0$

P4

Figure 4. Optimized B3LYP/6-31G* geometrical parameters of RC3, TS3, P4 and the atomic numbering for cycloaddition reaction(3). Lengths are in $\AA$ and angles in degree.

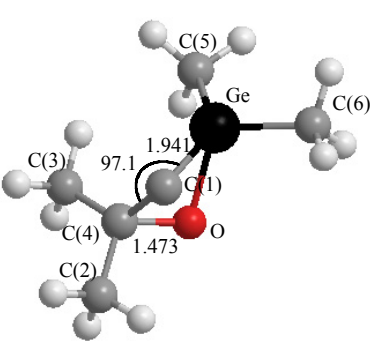

$\angle \mathrm{GeC}(1) \mathrm{C}(4) \mathrm{O}=45.3$ RC4

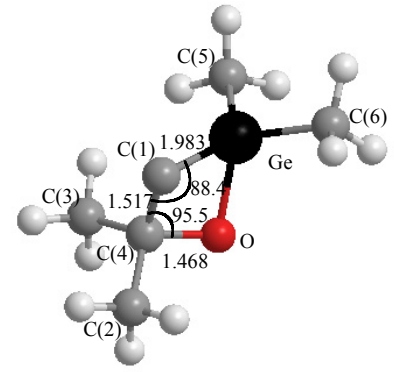

$\angle \mathrm{GeC}(1) \mathrm{C}(4) \mathrm{O}=28.2$

TS4.1

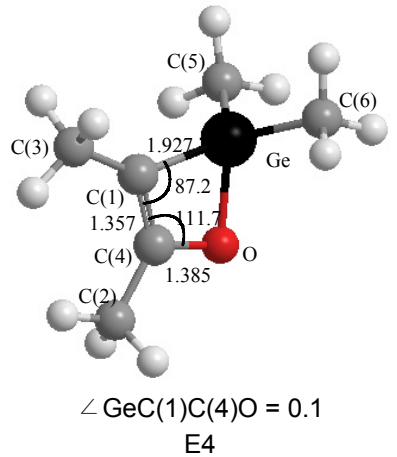

E4
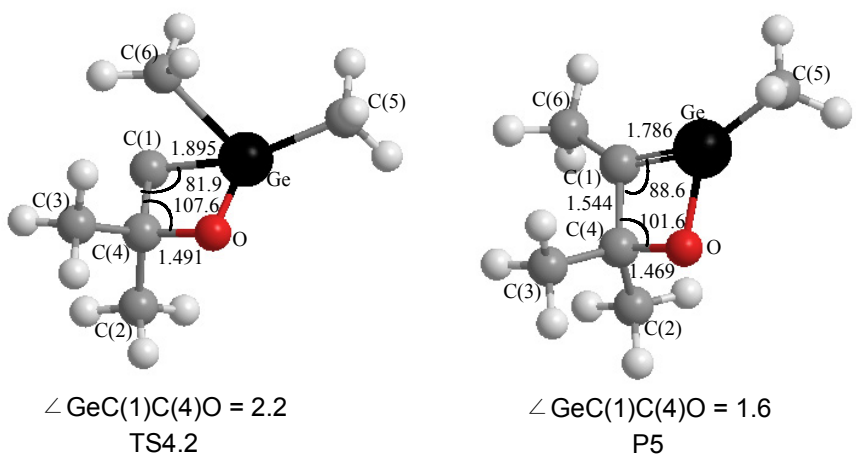

Figure 5. Optimized B3LYP/6-31G* geometrical parameters of RC4, TS4.1, E4, TS4.2, P5 and the atomic numbering for the species in cycloaddition reaction(4). Lengths are in $\AA$ and angles in degree.

and acetone are given in Fig. 3. The energies are listed in Table 1, and the potential energy surfaces for the cycloaddition reaction are shown in Fig. 2. The unique imaginary frequencies of the transition states TS2.1, TS2.2, TS2.3 and TS3.1 are 215.5i, 347.6i, 316.4i and 649.9i, respectively. Therefore, these transition states can be affirmed as the real ones. Their IRC (with the step-length of $0.1 \mathrm{amu}^{-1 / 2}$ bohr) analysis confirms that TS2.1 connects RC1 and E2.1; TS2.2 connects E2.1 and E2.2, TS2.3 connects E2.2 and P2, and TS3.1 connects E2.1 and P3.

It can be observed from Fig. 2 that the process of reaction (2) is as following: the first step is a barrier-free exothermic reaction of $117.4 \mathrm{~kJ} / \mathrm{mol}$, leading to an reactant complexe (RC1), which then isomerizes to a four-membered ring intermediate (E2.1) via a transition state TS2.1 with a barrier of $43.0 \mathrm{~kJ} / \mathrm{mol}$. Subsequently, the E2.1 isomerizes to the intermediate (E2.2) and $\mathrm{CH}_{3}$ - transfer product $\mathrm{P} 3$ via transition states TS2.2 and TS3.1 with energy barriers of 176.9 and $266.5 \mathrm{~kJ} / \mathrm{mol}$, respectively. The final step is an isomerization of E2.2 to the $\mathrm{CH}_{3}$ transfer product P2 via a transition state TS2.3, with an energy barrier of $90.6 \mathrm{~kJ} / \mathrm{mol}$. Because the energy barrier of E2.2 is $87.1 \mathrm{~kJ} / \mathrm{mol}$ higher than that of E2.1, the reaction E2.1 $\rightarrow$ E2.2 is forbidden in thermodynamics, this reaction will end in E2.1. So E2.1 $\rightarrow$ P3 should be the dominant reaction pathway. According to the comparison of reaction(2) with reaction(1), the energy 


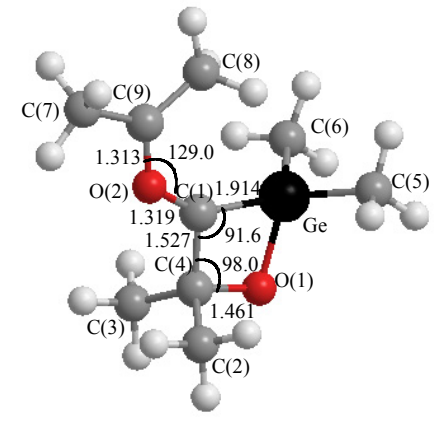

$\angle \mathrm{GeC}(1) \mathrm{C}(4) \mathrm{O}(1)=0.2$

$\angle \mathrm{O}(2) \mathrm{C}(1) \mathrm{C}(4) \mathrm{O}(1)=179.8$

$\angle \mathrm{C}(9) \mathrm{O}(2) \mathrm{C}(1) \mathrm{C}(4)=179.8$

RC5

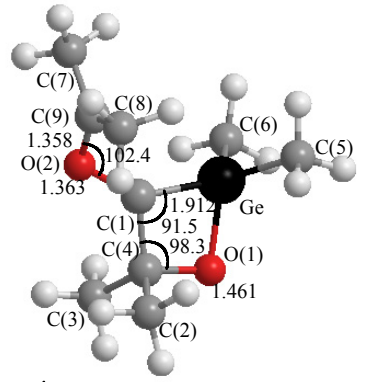

$\angle \mathrm{GeC}(1) \mathrm{C}(4) \mathrm{O}(1)=1.4$

$\angle \mathrm{O}(2) \mathrm{C}(1) \mathrm{C}(4) \mathrm{O}(1)=153.9$

$\angle \mathrm{C}(9) \mathrm{O}(2) \mathrm{C}(1) \mathrm{C}(4)=147.2$ TS5

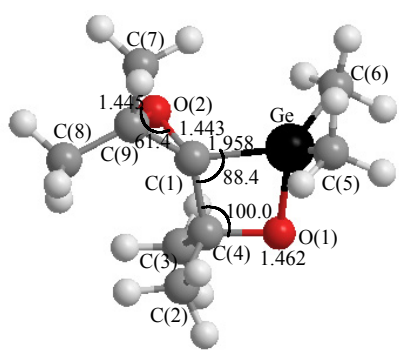

$\angle \mathrm{GeC}(1) \mathrm{C}(4) \mathrm{O}(1)=-4.7$

$\angle \mathrm{O}(2) \mathrm{C}(1) \mathrm{C}(4) \mathrm{O}(1)=121.1$

$\angle \mathrm{C}(9) \mathrm{O}(2) \mathrm{C}(1) \mathrm{C}(4)=123.5$

P6

Figure 6. Optimized B3LYP/6-31G* geometrical parameters of RC5, TS5, P6 and the atomic numbering for cycloaddition reaction(5). Lengths are in $\AA$ and angles in degree.

of TS1 is $11.5 \mathrm{~kJ} / \mathrm{mol}$ higher than that of TS2.1, so reaction(2) will be the dominant reaction channel.

Reaction(3): Channels of Forming Gemanic Bis-Heterocyclic Product (P4). In reaction(3), the active four-membered ring intermediate (E2.1) further reacts with acetone (R2) to form the germanic bis-heterocyclic compound P4. The geometric parameters for the reactant complexe ( $\mathrm{RC} 3)$, the transition state TS3 and the product $\mathrm{P} 4$ appearing in reaction(3) are given in Fig. 4. The energies are listed in Table 1. The potential energy surface for reaction(3) is illustrated in Fig. 2.

The unique imaginary frequency of the transition state TS3 is 220.6i, and therefore the transition state can be affirmed as the real one. IRC (with the step-length of 0.1 amu-1/2bohr) analysis confirms that TS3 connects RC3 and P4. According to Fig. 2, the process of reaction(3) is as following: on the basis of E2.1 formed from the reaction(2) between R1 and R2, E2.1 further reacts with acetone (R2) to form a complexe (RC3) through a barrier-free exothermic reaction of $28.2 \mathrm{~kJ} / \mathrm{mol}$. Then, $\mathrm{RC} 3$ isomerizes to a germanic bis-heterocyclic product $\mathrm{P} 4$ via $\mathrm{a}$ transition state TS3, for which the energy barrier is $63.5 \mathrm{~kJ} / \mathrm{mol}$. According to Fig. 2, reaction(3) and E2.1 $\rightarrow$ P3 in reaction(2) are competitive reactions, In reaction(2), E2.1 $\rightarrow$ P3 with an energy barrier of $266.5 \mathrm{~kJ} / \mathrm{mol}$; However, in reaction(3), E2.1 and $\mathrm{R} 2$ form $\mathrm{RC} 3$ just through a barrier-free exothermic reaction of $28.2 \mathrm{~kJ} / \mathrm{mol}$. Compared reaction(2) with reaction(3), it can be known that reaction(3) will be the dominant reaction channel.

Reaction(4): Channels of Forming Four-Membered Ring Complexe (RC4), Intermediate(E4) and $\mathrm{CH}_{3}$-Transfer Product (P5). The geometrical parameters for the reactant complexe (RC4), the transition states (TS4.1, TS4.2), intermediate (E4) and product (P5) appearing in reaction(4) between dimethylgermylene carbene and acetone are given in Fig. 5. The energies are listed in Table 1, and the potential energy surfaces for the cycloaddition reaction are shown in Fig. 2. The unique imaginary frequencies of the transition states TS4.1 and TS4.2 are $266.0 \mathrm{i}$ and $330.7 \mathrm{i}$, therefore, these transition states can be affirmed as the real ones. Their IRC (with the step-length of $0.1 \mathrm{amu}^{-1 / 2}$ bohr) analysis confirms that TS4.1 connects RC4 and E4, TS4.2 connects E4 and P5.

It can be observed from Fig. 2 that reaction(4) consists of three steps. The first one is a barrier-free exothermic reaction of $209.6 \mathrm{~kJ} / \mathrm{mol}$, leading to a twist four-membered ring complexe (RC4), which then isomerizes to a four-membered planar ring $\mathrm{CH}_{3}$-transfer intermediate $\mathrm{E} 4\left(\mathrm{CH}_{3}\right.$ transfers between $\mathrm{C}$ and C) via a transition state TS4.1, with an energy barrier of $14.2 \mathrm{~kJ} / \mathrm{mol}$. Finally the $\mathrm{E} 4$ isomerizes to $\mathrm{CH}_{3}$-transfer product $\mathrm{P} 5\left(\mathrm{CH}_{3}\right.$ transfers between $\mathrm{Ge}$ and $\left.\mathrm{C}\right)$ via transition state TS4.2, with barrier of $402.0 \mathrm{~kJ} / \mathrm{mol}$. Because the energy barrier of P5 is $151.3 \mathrm{~kJ} / \mathrm{mol}$ higher than that of $\mathrm{E} 4$, the reaction $\mathrm{E} 4 \rightarrow \mathrm{P} 5$ is forbidden in thermodynamics, this reaction will end in E4. According to the comparison of reaction(4) with reaction(3), the energy of TS2.1 is $28.8 \mathrm{~kJ} / \mathrm{mol}$ higher than that of TS4.1, so reaction(4) will be the dominant reaction channel.

Reaction(5): Channels of Forming Silicic Bis-Heterocyclic Product P6. In reaction(5), the active four-membered ring complexe RC4 further reacts with acetone (R2) to form the germanic bis-heterocyclic product $\mathrm{P} 6$. The geometric parameters for the complexe (RC5), the transition state TS5 and the product P6 appearing in reaction(5) are given in Fig. 6. The energies are listed in Table 1. And the potential energy surface for reaction(5) is illustrated in Fig. 2.

The unique imaginary frequency of the transition state TS5 is $161.3 \mathrm{i}$, and the transition state can therefore be affirmed as the real one. IRC (with the step-length of $0.1 \mathrm{amu}^{-1 / 2} \mathrm{bohr}$ ) analysis of TS5 confirms that TS5 connects RC5 and P6. According to Fig. 2, the process of reaction(5) is as following: on the basis of RC4 formed from the reaction(4) between R1 and R2, $\mathrm{RC} 4$ further reacts with acetone (R2) to form the RC5 through a barrier-free exothermic reaction of $165.4 \mathrm{~kJ} / \mathrm{mol}$. Then, RC5 isomerizes to a germanic bis-heterocyclic product $\mathrm{P} 6$ via a transition state TS5, for which the barrier is $56.0 \mathrm{~kJ} / \mathrm{mol}$. Compared reaction(5) with reaction(4), it is realizing that the two reactions form a mutual competition reaction due to scrambling for RC4 together. In reaction(4), RC4 isomerizes to E4 with an energy barrier of $14.2 \mathrm{~kJ} / \mathrm{mol}$; However, in reaction(5), RC4 and R2 form RC5 just through a barrier-free exothermic reaction of $165.4 \mathrm{~kJ} / \mathrm{mol}$. Compared reaction(5) with reaction(4), it can be known that reaction(5) will be the dominant reaction channel.

Theoretical Analysis and Explanation of the Dominant Reaction Channels. According to the above analysis, reaction(5) 


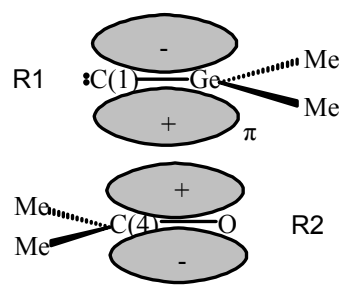

Figure 7. A schematic interaction diagram for the frontier orbitals of $\mathrm{Me}_{2} \mathrm{Ge}=\mathrm{C}:(\mathrm{R} 1)$ and $\mathrm{Me}_{2} \mathrm{C}=\mathrm{O}(\mathrm{R} 2)$.
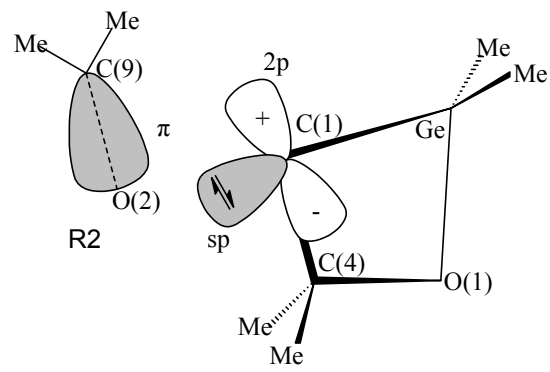

$\mathrm{RC} 4$

Figure 8. A schematic diagram for the frontier orbitals of RC4 and $\mathrm{Me}_{2} \mathrm{C}=\mathrm{O}(\mathrm{R} 2)$.

should be the dominant reaction channel of the cycloaddition reaction between singlet dimethyl-germylene carbene and acetone. namely:

$$
\mathrm{R} 1+\mathrm{R} 2 \longrightarrow \mathrm{RC} 4 \stackrel{+\mathrm{R} 2}{\longrightarrow} \mathrm{RC} 5 \stackrel{\mathrm{TS} 5}{\longrightarrow} \mathrm{P} 6 \quad \text { Reaction(5) }
$$

The mechanism of reaction(5) could be explained with the molecular orbital diagram (Figs. 7 and 8) and Figs. 5, 6. According to Figs. 5 and 7, as dimethyl-germylene carbene (R1) initially interacts with acetone (R2), the [2+2] cycloaddition of the bonding $\pi$-orbitals firstly results in a twist four-membered ring carbene RC4. In the conformation of RC4, atom $\mathrm{C}(1)$ is unsaturated. So, RC4 may further reacts with acetone (R2) to form the germanic bis-heterocyclic product P6. The mechanism of this reaction could be explained with the molecular orbital diagram (Fig. 8) and Fig. 6. When RC4 initially interacts with acetone (R2), C(1) in RC4 will be hybridized into $\mathrm{sp}^{2}$ hybrid orbital and reacts with acetone to form a complexe RC5. As the reaction goes on, the dihedral angles $\angle \mathrm{C}(9) \mathrm{O}(2) \mathrm{C}(1) \mathrm{C}(4)$ (RC5:
179.8 $8^{\circ}$, TS5: $\left.147.2^{\circ}, \mathrm{P} 6: 123.5^{\circ}\right)$ and $\angle \mathrm{C}(9) \mathrm{O}(2) \mathrm{C}(1)(\mathrm{RC} 5:$ $129.0^{\circ}$, TS5: $\left.102.4^{\circ}, \mathrm{P} 6: 61.4^{\circ}\right)$ gradually decrease, the $\mathrm{C}(9)-$ $\mathrm{O}(2)$ bond (RC5: $1.313 \AA$, TS5: $1.358 \AA$, P6: $1.445 \AA$ ) gradually lengthens. These changes finally make the $\mathrm{C}(1)$ in $\mathrm{RC} 5$ hybridize to $\mathrm{sp}^{3}$ hybrid orbital after the transition state TS5, forming the germanic bis-heterocyclic product P6.

\section{Conclusion}

On the basis of the potential energy surface obtained with the CCSD(T)//B3LYP/6-31G* method for the cycloaddition reaction between singlet dimethyl-germylene carbene and acetone, it can be predicted that the dominant reaction pathway of the cycloadditional reaction of forming germanic bis-heterocyclic compound is reaction(5). The process of this reaction is as following: (1) the two reactants firstly form a reactant complexe RC4 through a barrier-free exothermic reaction of $209.6 \mathrm{~kJ} / \mathrm{mol}$; (2) $\mathrm{RC} 4$ further reacts with acetone (R2) to form a complexe RC5, which is also a barrier-free exothermic reaction of $165.4 \mathrm{~kJ} / \mathrm{mol}$; (3) RC5 then isomerizes to a germanic bis-heterocyclic product P6 via a transition state TS5 with an energy barrier of 56.0 $\mathrm{kJ} / \mathrm{mol}$.

\section{Reference}

1. Stang, P. J. Acc. Chem. Res. 1982, 15, 348.

2. Stang, P. J. Chem. Rev. 1978, 78, 384.

3. Krishnan, R.; Frisch, M. J.; Pople, J. A. Chem. Phys. Lett. 1981, 79, 408.

4. Frisch, M. J.; Krishnan, R.; Pople, J. A. Chem. Phys. Lett. 1981, $81,421$.

5. Wardrop, D. J.; Zhang, W. Tetrahedron Lett. 2002, 43, 5389.

6. Feldman, K. S.; Perkins, A. L. Tetrahedron Lett. 2001, 42, 6031.

7. Apeloig, Y.; Karni, M.; Tang, S. P. J.; Fox, D. P. J. Am. Chem. Soc. 1983, 105, 4781.

8. Fox, D. P.; Tang, S. P. J.; Apeloig, Y.; Karni, M. J. Am. Chem. Soc. 1986, 108, 750 .

9. Lu, X. H.; Wang, Y. X. J. Phys. Chem. A 2003, 107, 7885.

10. Lu, X. H.; Wang, Y. X.; J. Mol. Struct. Theochem 2004, 686, 207.

11. Lu, X. H.; Wu, W. R.; Yu, H. B.; Yang, X. L.; Xu, Y. H. J. Mol. Struct. Theochem 2005, 755, 39.

12. Lu, X. H.; Yu, H. B.; Wu, W. R.; Xu, Y. H. Int. J. Quantum Chem. 2007, 107, 451.

13. Lu, X. H.; Xiang, P. P.; Wu, W. R.; Che, X. J. Mol. Struct. Theochem 2008, 853, 82.

14. Lee, C.; Yang, W.; Parr, R. G. Phys. Rev. B 1988, 37, 785.

15. Fukui, K. J. Phys. Chem. 1970, 74, 4161.

16. Ishida, K.; Morokuma, K.; Komornicki, A. J. Chem. Phys. 1981, $66,2153$. 